\title{
Spectrum of MDP Bone Scan in Paediatric Patients - Experience at NINMAS \\ ${ }^{1}$ Pupree Mutsuddy, ${ }^{1}$ Shamim M F Begum, ${ }^{1}$ Nasreen Sultana, ${ }^{1}$ Rahima Parveen, ${ }^{1}$ Nabeel Fahmi Ali, \\ 2 Amardeep Chaudhury and ${ }^{1}$ Layla Saroware Banu \\ ${ }^{1}$ National Institute of Nuclear Medicine and Allied Sciences (NINMAS), Dhaka, Bangladesh \\ 2 IAEA Fellow
}

Correspondence Address : Pupree Mutsuddy Senior Medical Officer, National Institute of Nuclear Medicine and Allied Sciences,

Dhaka, Email : pupreesomc40@gmail.com

\begin{abstract}
Objective: To assess the clinical indications and spectrum of MDP bone scan findings in paediatric patients referred to the National Institute of Nuclear Medicine and Allied Sciences (NINMAS).

Materials and Methods: Paediatric patients, age ranged from 2-18 years referred to NINMAS from January 2014 to November 2015 for bone scintigraphy were included in this study. All patients had ${ }^{99 m}$ Tc MDP bone scan for various clinical indications. The spectrum of clinical indications and bone scan findings were recorded and analyzed.

Results: Total 2323 bone scans with ${ }^{99}$ Tc MDP were done in NINMAS in the above mentioned period. Among them 91 $(3.917 \%)$ cases were in paediatric age group. Of which 82 $\mathbf{9 0 . 1 1 \% )}$ patients with known malignancy were referred for radionuclide skeletal survey. The most common clinical indications were osteosarcoma $30(32.96 \%)$ cases and Ewing's sarcoma $25(27.47 \%)$ cases followed by five neuroblastoma $(5.49 \%)$, four $(4.39 \%)$ rhabdomyosarcoma, three $(3.29 \%)$ Langerhans cell histocytosis and rest others. Bone scan was positive in $58(63.7 \%)$ cases and normal in $33(36.3 \%)$ cases. Out of 58 cases 38 had features of primary bony lesion, 10 cases had multiple metastases, four cases had primary bone tumour of Ewing's sarcoma as well as metastases.

Conclusion: Bone scan is a popular imaging modality for skeletal survey of paediatric patients in malignancy, both primary and metastatic bone diseases. Bone scanning in paediatric patients contributes a major role in detecting the cause and localizing the pathology of bone. High quality imaging, interpreted by physicians familiar with paediatric diseases, correlation with clinical records and other imaging are mandatory to maximize the benefit.
\end{abstract}

Keywords: MDP Bone scan, Paediatric, Osteosarcoma, Childhood tumour

\section{INTRODUCTION}

The radionuclide bone imaging using ${ }^{99 \mathrm{~m}} \mathrm{Tc}$ MDP (methylene diphosphonate) is a quick, relatively inexpensive, widely available, and exquisitely sensitive and is invaluable in the diagnostic evaluation of numerous pathologic conditions of bone $(1,2)$. It is the second most frequently performed radionuclide study in paediatric patients. There are a wide variety of indications for ${ }^{99 \mathrm{~m}} \mathrm{Tc}$ MDP bone scan with maximum advantages and minimum disadvantages. It is valuable in the diagnosis of inflammatory conditions, osteomyelitis, septic arthritis, trauma, vascular insult, occult bone pain, hip pain, child abuse and malignant diseases $(3,4,5)$. In paediatric patients most of the bone scan is performed with a diagnosis of malignancy, both primary and metastatic bone diseases. Bone scan plays an integral part in tumour staging and management. In recent years Nuclear Medicine methods are also applied in determining the response of tumour to the treatment. The most commonly used radiopharmaceutical is ${ }^{99 \mathrm{~m}} \mathrm{Tc}$ MDP for planar bone scan. Single photon emission computed tomography (SPECT) provides improved spatial resolution of imaging using gamma emitters and, moreover, it can be fused with MRI and CT, thus giving anatomic dimension to nuclear medicine imaging (6). No published data on the incidence of paediatric cancer is available in Bangladesh. paediatric cancer or childhood cancer means cancer in children which are rare and representing between $0.5 \%$ and $4.6 \%$ of all cancers. Cancer is the second most common cause of death in children, accounting for approximately $10 \%$ of all childhood deaths. The overall incidence rates of childhood cancer vary between 50 and 200 per million children across the world $(7,8)$. 
This retrospective study was performed to assess the spectrum of MDP bone scan findings and nature of clinical indications of MDP skeletal survey in paediatric patients referred to a tertiary centre.

\section{MATERIALS AND METHODS}

This retrospective study was carried out in National Institute of Nuclear Medicine and Allied Sciences, Dhaka, from January 2014 to November 2015. Total 2323 bone scans were performed at NINMAS and out of them 91 paediatric patients were enrolled (48 males and 43 females, age range 2-18 years, mean age 11.37 \pm 4.91 years) in this study. All paediatric patients between 0-18 years of age referred for bone scan with various clinical indications were included in this study. The WHO recommended standard age of paediatric patient is $0-18$ years (9). Whole body bone scan was performed on anterior and posterior projections in each patient after intravenous injection of ${ }^{99 \mathrm{~m}} \mathrm{Tc}$ MDP. If needed, three phase bone scan and spot views were obtained by using Siemens E.cam dual head gamma camera. The available clinical data, detail history and related investigation results and imaging findings were recorded from the departmental data archiving system. Images of all patients were reviewed and interpreted by at least two senior nuclear medicine specialists. The spectrum of clinical indications of bone scan and nature of scan findings were recorded for analysis.

\section{RESULTS}

Total 91 paediatric patients, 48 males and 43 females (Table 1), age range 2-18 years, mean age $11.37 \pm 4.91$ years were referred for radionuclide skeletal survey with various clinical indications which were predominantly malignant. The most common clinical indications were osteosarcoma 30 (32.96\%) cases and Ewing's sarcoma 25 (27.47\%) cases followed by five (5.49\%) neuroblastoma, four (4.39\%) rhabdomyosarcoma, three (3.29\%) Langerhans cell histocytosis and rest others (Table 2). Bone scan was positive in 58(63.7\%) cases and normal in 33(36.3\%) cases (Table 3). Out of 58 cases 38 cases had features of primary bony lesion, 10 cases had multiple metastases, among four cases had primary bone tumour of Ewing's sarcoma with metastases and solitary bone lesion suspicious for metastasis were present in three cases (Table 4). The childhood tumour was present in 69 cases with osteosarcoma predominance and the distribution of childhood tumour in different age group is summarized in Table 5. Metastatic bone involvement was more prevalent in Ewing's sarcoma; in 24\% cases comparing to osteosarcoma, which was $13.3 \%$. Distribution of bony lesion according to the skeletal site of involvement shown in Table 6, where appendicular bony involvement was predominant $(60.35 \%)$.

Table 1: Distribution of number and percentage of sex in study population $(\mathrm{n}=91)$

\begin{tabular}{|l|l|l|}
\hline Sex & Number of patient & Percentage (\%) \\
\hline Male & 48 & $52.75 \%$ \\
\hline Female & 43 & $47.25 \%$ \\
\hline
\end{tabular}

Table 2: Distribution of frequency and percentage of clinical indications of MDP bone scan in study population $(\mathbf{n}=91)$

\begin{tabular}{|l|l|r|}
\hline Types & $\mathrm{n}=91$ & Percentage (\%) \\
\hline Osteosarcoma & 30 & $32.967 \%$ \\
\hline Ewing's Sarcoma & 25 & $27.472 \%$ \\
\hline Neuroblastoma & 05 & $5.494 \%$ \\
\hline Rhabdomyosarcoma & 04 & $4.395 \%$ \\
\hline $\begin{array}{l}\text { Langerhans cell } \\
\text { histocytosis }\end{array}$ & 03 & $3.297 \%$ \\
\hline $\begin{array}{l}\text { Nasopharyngeal } \\
\text { carcinoma }\end{array}$ & 02 & $2.197 \%$ \\
\hline Renal cell carcinoma & 02 & $2.197 \%$ \\
\hline Nephroblastoma & 02 & $2.197 \%$ \\
\hline Brain tumour & 02 & $2.197 \%$ \\
\hline Giant cell tumour & 02 & $2.197 \%$ \\
\hline $\begin{array}{l}\text { Malignant peripheral } \\
\text { sheath tumour }\end{array}$ & 01 & $1.098 \%$ \\
\hline Retinoblastoma & 01 & $1.098 \%$ \\
\hline Carcinoma of rectum & 01 & $1.098 \%$ \\
\hline $\begin{array}{l}\text { Metastatic papillary } \\
\text { carcinoma of thyroid }\end{array}$ & 01 & $1.098 \%$ \\
\hline Carcinoma of breast & 01 & $1.098 \%$ \\
\hline Non malignant conditions & 09 & $9.90 \%$ \\
\hline
\end{tabular}


Table 3: Distribution of bone scan findings among the study population $(\mathrm{n}=91)$

\begin{tabular}{|l|l|l|}
\hline Findings & $\mathrm{n}=91$ & Percentage (\%) \\
\hline $\begin{array}{l}\text { Positive /abnormal bone } \\
\text { scan }\end{array}$ & 58 & $63.7 \%$ \\
\hline Normal bone scan & 33 & $36.3 \%$ \\
\hline Total & 91 & $100 \%$ \\
\hline
\end{tabular}

Table 4: Distribution of nature of bony lesion among the positive or abnormal bone $\operatorname{scan}(n=58)$

\begin{tabular}{|l|l|l|l|}
\hline & Findings & $\mathrm{n}=58$ & Percentage (\%) \\
\hline $\begin{array}{l}\text { Positive } \\
\text { /abnormal } \\
\text { bone scan }\end{array}$ & Primary bony lesion & 38 & $65.52 \%$ \\
\cline { 2 - 4 } & $\begin{array}{l}\text { Primary bony lesion with } \\
\text { metastasis }\end{array}$ & 4 & $6.91 \%$ \\
\cline { 2 - 4 } & Multiple bone metastases & 10 & $17.24 \%$ \\
\cline { 2 - 4 } & Solitary bony lesion & 3 & $5.17 \%$ \\
\cline { 2 - 4 } & $\begin{array}{l}\text { Significant response/flare } \\
\text { phenomena }\end{array}$ & 1 & $1.72 \%$ \\
\cline { 2 - 4 } & Chronic ostcomyclitis & 1 & $1.72 \%$ \\
\cline { 2 - 4 } & Benign bony lesion & 1 & $1.72 \%$ \\
\hline Total & & 58 & $100 \%$ \\
\hline
\end{tabular}

\section{Table 5: Distribution of childhood tumour in} different age group ( $n=69)$

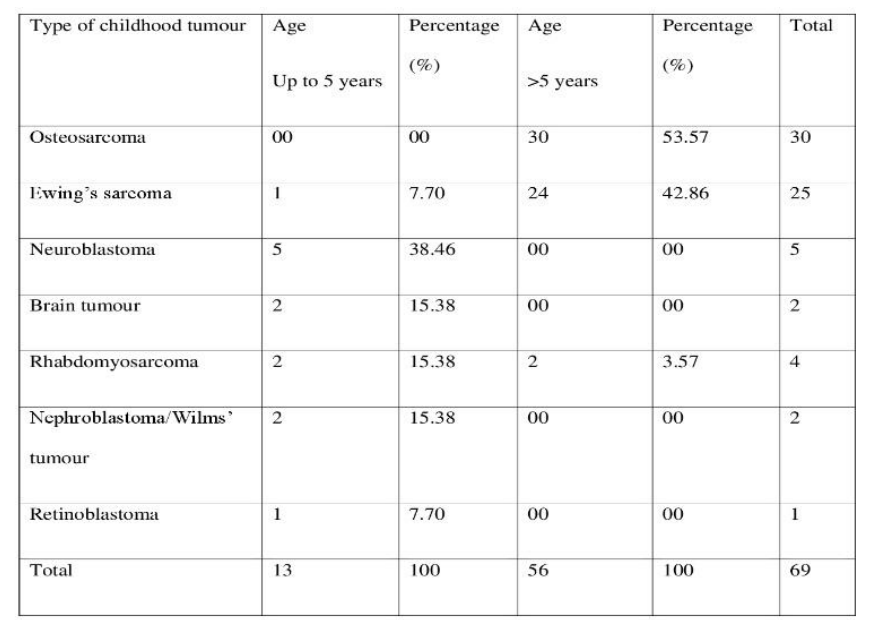

Table 6: Distribution of bony lesion according to the skeletal site of involvement $(n=58)$

\begin{tabular}{|l|l|l|}
\hline Site & $\mathrm{n}=58$ & Percentage (\%) \\
\hline Skull & 6 & $10.34 \%$ \\
\hline Appendicular bone & 35 & \\
& $\begin{array}{l}\text { Lower limb:27;(46.55\%) } \\
\text { Upper limb: } 8 ;(13.8 \%)\end{array}$ & \\
& & $60.35 \%$ \\
\hline Axial Bone & 17 & $29.31 \%$ \\
\hline
\end{tabular}

\section{DISCUSSION}

Radionuclide imaging provides both functional as well as anatomical information (3). Numerous studies have confirmed that it is considerably more sensitive than conventional radiography for detecting skeletal abnormalities. It is valuable in the diagnosis of inflammatory conditions, trauma, vascular insult, occult bone pain and malignant diseases (9). The application of radionuclide skeletal survey in the management of malignant diseases in children consists of detecting and estimating the degree of tumour spread (10).

After introduction of Technetium-99m labeled $\left({ }^{99 \mathrm{~m}} \mathrm{Tc}\right.$ ) polyphosphonate compounds like methylene diphosphonate (MDP), bone scan has become a practical investigation in children. The biodistribution of MDP in children is different to adults with higher activity in the growth plates. ${ }^{99 \mathrm{~m}} \mathrm{Tc}$ MDP has rapid clearance from blood and soft tissue and high affinity for bone with fast uptake. Accumulation of ${ }^{99 \mathrm{~m}} \mathrm{Tc}$ MDP in bone relate to the amount of blood flow to the region, but uptake is primarily controlled by the amount of osteogenic activity, being much higher in areas of active bone formation or repair compared to mature bone. Decreased activity is seen in areas of reduced blood flow or infarction. Diminished uptake or cold areas are also seen in regions of very aggressive metastases, which are associated with severe destruction. The positive scan indicates presence of pathology but does not indicate the etiology of the lesion. Clinical presentation plays a major role in drawing inference of bone scan findings by narrowing the spectrum of differential diagnosis. Bone scan has the advantage of whole body imaging with single injection and scans become positive many days before radiographic changes. The early localization helps to focus on lesion for further investigations with CT or MRI (11).

This study shows that 91 bone scans were performed in the paediatric patients having known malignancy and specially bone tumour. The most common clinical indications of paediatric bone scan were osteosarcoma in 30 (32.96\%) cases and Ewing's sarcoma in 25 (27.47\%) cases. Bone tumour comprises $7.3 \%$ of all malignancies 
among paediatric patients with almost $90 \%$ cases with osteosarcoma was reported by Jabeen $\mathrm{S}$ et al. This study also accords with Mirabello study, where osteosarcoma was reported predominantly in adolescent and young adults and accounts for $5 \%$ of childhood tumours $(12,13)$. In the workup of childhood malignancies like osteosarcoma, Ewing's sarcoma, neuroblastoma and rhabdomyosarcoma, bone scan is recommended to evaluate the primary lesion, to indentify metastatic involvement and to find out multifocal diseases. Bone scan is also recommended for pre-therapy survey and sometimes to evaluate the response of therapy $(14,15,16)$. In this study, primary bone lesion was evident in 41 cases; four cases had primary tumour associated with metastases. One case with Ewing's sarcoma showed response of therapy in the follow up bone scan comparing to the previous bone scan after chemotherapy.

Bone scan is the investigation next to radiography for the osteomyelitis, septic arthritis and trauma. It is recommended when the radiological evaluations are negative. The sensitivity of three phase bone scan is $95 \%$ for the osteomyelitis with reported accuracy of 75 $\%$ or better and useful in differentiating osteomyelitis from cellulitis (17).

\section{CONCLUSION}

Bone scan in paediatric patients contributes a major role in detecting the cause and localizing the pathology of bone. It is a popular imaging modality for skeletal survey of paediatric patients in malignancy, both primary and metastatic bone diseases. High quality imaging, interpreted by physicians familiar with paediatric diseases, correlation with clinical records and other imaging modalities are mandatory to maximize the benefit.

\section{REFERENCES}

1. Genant HK, Bautovich GJ, Singh M, Lathrop KA, Harper PV. Bone-seeking radionuclides: an in vivo study of factors affecting skeletal uptake. Radiology 1974; 113:373-82.

2. McAfee JG, Reba RC, Majd M. The musculoskeletal system. In:Wagner HN, Jr, Szabo Z, Buchanan JW, eds. Principles of nuclear medicine. 2nd ed. Philadelphia, Pa: Saunders, 1995; 986-1012.

3. Conway J J. Radionuclide bone imaging in paediatrics. paediatric Clin North Am 1977; 24:701-12.

4. Murry IP. Bone scanning in the child and young adult. Part-I, Skeletal Radiol 1980;5:1-14.

5. Murry IP. Bone scanning in the child and young adult. Part-II, Skeletal Radiol 1980;5:1-14.

6. Wegner EA, Barrington SF, Kingston JE, Robinson RO, Ferner RE, Taj $\mathrm{M}$ et al. The impact of PET scanning on management of paediatric oncology patients. Eur J Nucl Med Mol Imaging 2005; 32:23-30.

7. Gurney JG, Severson RK, Davis S, Robison LL. Incidence of cancer in children in the United States. Cancer. 1995;75:2186-95.

8. IARC World Cancer Report 2014 Lyon France.

9. Hage WD, Aboulafia AJ, Aboulafia DM. Incidence, location and diagnostic evaluation of metastatic bone disease. Orthop Clin North Am 2000; 31:515-28.

10. David L. Gilday, B.Eng, Judith M. Ash,Bernard J. Reilly. 1977 Volume 123, Issue 2. http://dx.doi.org/10.1148/123.2.399

11. Helen C. Radionuclide bone scanning. Archives of Disease in Childhood 1993; 69:160-65.

12. Jabeen S1, Haque M, Islam MJ, Talukder MH. Profile of paediatric malignancies: A five year study. J Dhaka Med Coll.2010;19(1):33-38.

13. Mirabello L, Troisi RJ, Savage SA: Osteosarcoma incidence and survival rates from 1973 to 2004: data from the Surveillance, Epidemiology and End Results Program. Cancer. 2009;115(7):1531-43.

14. Emedicine.medscape.com/article/1256857-workup Oct 21, 2015

15. Emedicine.medscape.com/article/990378-workupJun 18, 2014

16. Emedicine.medscape.com/article/988803-workupJun 16, 2014

17. Schauwecher DS. The scintigraphic diagnosis of osteomyelitis. AJR 1992; 158:9-19. 